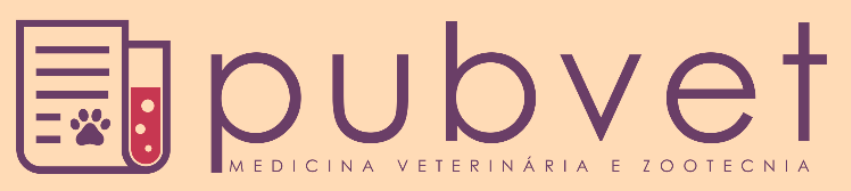

https://doi.org/10.31533/pubvet.v15n10a946.1-11

\title{
Fisiologia e histopatologia do pâncreas na diabetes mellitus canina: Revisão
}

\author{
Karine Aparecida Spuri Batista ${ }^{1 * \bullet}$, Camila Buzzo dos Santos ${ }^{1}$, Michele Samira Salman Shihadeh, \\ Denise Ribeiro de Toledo ${ }^{1}$, Eduardo D'Oliveira Landa ${ }^{1}$, Patrícia Franciscone Mendes ${ }^{2} \bullet$
}

${ }^{I}$ Discente do Curso de Medicina Veterinária - Centro Universitário das Américas. São Paulo - São Paulo - Brasil.

${ }^{2}$ MSc. DR. Docente do Curso de Medicina Veterinária - Centro Universitário das Américas. São Paulo - São Paulo - Brasil.

*Autor para correspondência, E-mail: karinespuri@gmail.com

Resumo. A Diabetes Mellitus Canina (DMC) é representada como um grupo de doenças metabólicas autoimunes de etiologia multifatorial. Na DMC ocorre uma deficiência relativa ou absoluta de insulina que leva a uma insuficiência das células em obter e utilizar a glicose. Na maioria dos casos, os cães diagnosticados serão insulinodependentes por toda sua vida, e, quando não tratados a progressão da doença levará o animal à óbito. O objetivo desta pesquisa foi estudar a histopatologia e fisiologia do pâncreas para compreender a etiopatogenia da DMC, a partir da descrição das alterações patológicas pancreáticas decorrentes da mesma ou que favorecem sua ocorrência. A metodologia desta pesquisa foi a de revisão de literatura a partir de livros e produção científica em Medicina Veterinária, com base em pesquisa relacionada com as seguintes palavras chaves: Diabetes Mellitus Canina; Patologias Pancreáticas; Endocrinopatias em cães; em algumas bases de dados como: SciELO.org e Google Academy, nos últimos 12 anos. Atualmente não há um critério internacionalmente definido para a classificação da diabetes em pequenos animais. É comum a classificação da DMC segundo modelo humano; porém, alguns autores defendem o uso de DMC primária e secundária. As principais alterações histológicas do pâncreas em cães com DMC incluem a destruição parcial ou total das ilhotas de Langerhans, vacuolização e/ou degeneração hidrópica, presença de infiltração leucocitária, embora divergente entre autores. Os anticorpos quando imunomediada são descritos também depósitos amiloides, predispondo à glucotoxicidade. Algumas alterações pancreáticas são advindas da DMC como consequência; porém, o contrário também ocorre. Os mecanismos fisiológicos autoimunes em conjunto com fatores genéticos e ambientais, drogas antagonistas da insulina e doenças adjacentes têm um papel importante para o desenvolvimento e a progressão da DMC, tendo como resultado final a perda irreversível de função das células $\beta$-pancreáticas.

Palavras-chave: Diabetes mellitus canina, DMC, endocrinopatias, pancreatite patológica

\section{Physiology and histopathology of pancreas in canine diabetes mellitus: Review}

\begin{abstract}
Canine Diabetes Mellitus (CDM) is represented as a group of autoimmune metabolic diseases of multifactorial etiology. In CDM there is a relative or absolute deficiency of insulin that leads to a failure of the cells to obtain and use glucose. Are most cases, diagnosed dogs will be insulin dependent for all life, and when the disease is not treated will the consequence is death. The objective of this review was to study the histopathology and physiology of the pancreas to understand the etiopathogenesis of CDM, based on the description of pancreatic pathological changes resulting from it or that favor its occurrence. The methodology of this research was to review literature from books and scientific production in veterinary medicine, based on research related to the following. Currently, there is no internationally defined criterion for the classification of diabetes in small animal. Classification of CDM according to the human model is common, bit some
\end{abstract}


authors defend the use of primary and secondary CDM. The main histological alterations of the pancreas in dog with CDM include partial or total destruction of the islets of Langerhans, vacuolization and/or hydropic degeneration, presence of leukocyte infiltration, although divergent between authors, and antibodies when immune-mediated; amyloid deposits are also described, predisposing to glucotoxity. Some pancreatic changes are caused by CDM as a consequence, but the opposite also occurs. The autoimmune physiological mechanisms together with genetic and environmental factors, insulin antagonist drugs and adjacent diseases play an important role in the development and progression of CDM, resulting in the irreversible loss of function of $\beta$-pancreatic cells.

Keywords: Canine diabetes mellitus, CDM, endocrinopathies, pancreatic pathology

\section{Introdução}

A diabetes é uma doença endócrina multifatorial e complexa, de alta morbidade e mortalidade, de humanos e animais (Sparkes et al., 2015). Dados de 2019 da International Diabetes Federation (IDF) afirmam que, mundialmente, uma em cada 11 pessoas são portadoras da doença e atribuem à diabetes cerca de 4,2 milhões de óbitos humanos no mundo todo (IDF, 2019). No Brasil, também em 2019, a Pesquisa Nacional de Saúde estimou que 7,7\% da população acima de 18 anos tiveram diagnóstico médico de diabetes, o equivalente a cerca de 12,3 milhões de pessoas (IBGE, 2019). Seguindo essa curva, as diabetes vêm sendo diagnosticada progressivamente e se mostra como uma doença de altíssima prevalência na clínica de pequenos animais, porém sua patogênese ainda é mal compreendida, não havendo nenhuma classificação e/ou critério internacional para seu diagnóstico (Almeida, 2012).

$\mathrm{Na}$ literatura encontramos a descrição de diabetes humana em dois tipos: DM tipo I (DMID) ou insulinodependente e DM tipo II (DMNID), ou não insulinodependente; porém, na Medicina Veterinária, utiliza-se mais os termos Diabetes Mellitus de causa primária ou secundária, devido ao fato de que a insulina é a base do tratamento em animais diagnosticados (Gilor et al., 2016; Marco et al., 1999). Todavia, não é raro alguns autores associarem a DM canina com a DM tipo I humana. Entretanto, deve-se ressaltar que enquanto essa doença em humanos é diagnosticada em indivíduos jovens, na espécie canina a média de idade é de 10 anos. A DM canina juvenil vem sendo associada às Diabetes Autoimune Latente do Adulto (LADA), uma vez que a patogenia de ambas se equivale (ABEV, 2018).

Nesta revisão, abordamos essa discussão a propósito da classificação da DMC, e ainda, realizamos o estudo histopatológico e fisiológico do pâncreas a partir da literatura já publicada, para compreender a etiopatogenia da DMC com base na descrição das alterações patológicas pancreáticas que são ocasionadas em decorrência da mesma ou, que possam vir a favorecê-la.

\section{Histologia e fisiologia do pâncreas}

O pâncreas é uma glândula retroperitoneal mista, altamente vascularizada e inervada, situada na parte dorsal da cavidade abdominal e pode ser dividida em três partes: corpo, lobo direito e lobo esquerdo (Köning \& Liebich, 2011; Sisson et al., 1986). De acordo com Dyce et al. (2004) sua aparência é amarelada, assemelhando-se com uma glândula salivar, porém apresenta consistência mais amolecida e mais frouxamente entrelaçada (Moreira et al., 2017). Em carnívoros, o pâncreas é delgado com formato em "V", sendo o lobo esquerdo mais curto, mais espesso e mais dorsal que o lobo direito, tendo sua origem no omento maior, já o lobo direito é mais extenso, seguindo o duodeno descendente dentro do mesoduodeno. $\mathrm{O}$ suprimento sanguíneo arterial pancreático é proveniente das artérias esplênicas e pancreáticas duodenais e a drenagem do sangue venoso se dá através da veia porta hepática (Hugen, 2017; Tavernari \& Mendes, 2009).

O pâncreas é coberto por uma capsula fina de tecido conjuntivo frouxo, cujo parênquima é formado por ácinos pancreáticos e por ilhotas (de Langerhans), separadas por estroma. É organizado em lóbulos, pelos septos interlobulares de tecido conjuntivo contendo ductos, vasos sanguíneos, nervos e corpúsculos lamelares (receptores sensoriais). Por ser uma glândula mista, o pâncreas possui funções endócrinas e exócrinas. A primeira resulta de atividade da segunda e ambas estão envolvidas no funcionamento do trato gastrointestinal (Köning \& Liebich, 2011). O tecido pancreático é formado por glândulas serosas acinares compactadas, chamadas de ácinos pancreáticos, formadas por epitélio 
simples, sendo as células acinares, piramidais, com uma porção basal mais espessa e uma superfície apical delgada, que fica ao redor de um pequeno lúmen central (Jennings et al., 2017).

Cerca de 95\% do pâncreas é composto desse tecido exócrino e o produto exócrino do pâncreas é chamado de suco pancreático. As células acinares possuem grânulos de zimogênio (também chamados de pró-enzimas) que sintetizam e secretam enzimas digestivas inativas (amilases, lipases, proteases etc) pela exocitose, enzimas estas que são ativadas quando chegam à luz do duodeno. O suco pancreático é conduzido para o duodeno por um ou mais ductos, e depende da espécie (Dukes et al., 2006; Herrtage, 2001; Marco, 2015), as células presentes nestes ductos produzem fluidos ricos em bicarbonato e mucina, que são utilizados na neutralização do conteúdo ácido do estomago (Jennings et al., 2017).

Os ductos intercalares, que saem do ácino, são ductos curtos com um pequeno lúmen, revestidos por epitélio simples escamoso, eles drenam nos ductos intralobulares, que por sua vez são revestidos por epitélio colunar simples pavimentoso, estes ductos irão drenar o conteúdo em outros ductos de maior calibre chamados ductos interlobulares, que por sua vez são revestidos por tecido colunar escamoso que vai se estratificando a medida que o calibre aumenta, e por fim, estes ductos irão desembocar no ducto pancreático principal e/ou acessório (Banks \& Rangel, 1986; Eurell \& Frappier, 2012; Samuelson, 2011). No cão, são dois ductos, o ducto pancreático, mais ventral que se abre no duodeno próximo ao ducto biliar da papila duodenal maior e o ducto acessório, mais dorsal, que se abre na face oposta do anterior, na papila duodenal menor (Köning \& Liebich, 2011).

A porção endócrina é organizada em pequenas ilhotas, chamadas de ilhotas de Langerhans, que são acúmulos de células entre os ácinos exócrinos. Estas ilhotas, amplamente vascularizadas e inervadas, contém quatro tipos celulares diferentes e cada um produz um tipo de hormônio diferente, são elas $\alpha, \beta$ e $\delta$ (D), F ou PP. E, por mais que sejam diferentes entre si, todas estão envolvidas no controle do metabolismo, principalmente no que se refere a homeostase da glicose; sendo que: as células $\alpha$ são as produtoras de glucagon, as células $\beta$ produzem insulina, as células $\delta$ (D) são as produtoras de somatostatina e as F ou PP produzem o polipeptídio pancreático (Cunningham, 2011).

Os hormônios principais de regulação das secreções pancreáticas são a secretina e a colecistoquinina (CCK), sintetizadas no intestino delgado, porém, estas células das ilhotas de Langerhans são inervadas por fibras do sistema nervoso simpático e parassimpático, o que permite também ao sistema nervoso autônomo (SNA), via nervo vago, modular a secreção destes hormônios pancreáticos (Marco et al., 1999). Os neurotransmissores provenientes das fibras parassimpáticas são a Acetilcolina (ACh), o Polipetídio Intestinal Vasoativo (VIP) e o Polipeptídio Liberador de Gastrina (GRP). A ACh estimula a liberação de glucagon, insulina e o polipeptídio pancreático e sua ação se dá após a ligação no receptor muscarínico da célula $\beta$. O mesmo ocorre com o GRP que além destes, estimula também a secreção da somastostatina. Quanto ao VIP, este possui mecanismos pouco conhecidos (Jennings et al., 2017).

Já os neurotransmissores provenientes das fibras simpáticas são a noradrenalina, a galanina e o neuropeptídeo Y. A noradrenalina inibe a secreção de insulina e estimula a secreção de glucagon. A galanina e o neuropeptídio Y, agem inibindo a secreção de insulina. Acredita-se que existam outros mecanismos regulatórios da secreção hormonal das ilhotas de Langerhans além destes mencionados, porém isto não está totalmente esclarecido pela literatura (Jennings et al., 2017). A somatostatina (sintetizado pelas células $\delta$-pancreáticas), é a reguladora da secreção das células $\alpha$ e $\beta$-pancreáticas, que secretam os principais hormônios das ilhotas de Langerhans: a insulina e o glucagon. A interação destes dois hormônios é o que regula o metabolismo da glicose, ácidos graxos livres, aminoácidos e outros substratos (Rocha, 2018; Rucinsky et al., 2010).

A insulina é um peptídeo que age no controle da glicemia, sendo secretada em resposta à hiperglicemia, para que ocorra a diminuição da glicose no sangue; assim, que essa diminuição de glicose ocorre, a secreção de insulina cessa, e o glucagon é liberado, agindo como um antagonista à insulina neste controle glicêmico (Balarin et al., 2005). Tanto a insulina quanto o glucagon agem, principalmente, sobre o fígado, massa muscular e tecido adiposo (Bloom \& Rand, 2014; Rocha, 2018). A insulina é um hormônio anabolizante com efeitos orgânicos extremamente importantes no metabolismo dos carboidratos e lipídios pela ingestão de enzimas celulares especificamente em hematócitos e o transporte de glicose através da membrana plasmática das células adiposas e também na musculatura esquelética (Moreira et al., 2017). A regulação dos níveis de glicemia aumenta a absorção de glicose no músculo 
esquelético, gordura e inibe a gliconeogênese hepática e a cetogênese; estimula também o crescimento e a diferenciação celular pela síntese de glicogênio e proteínas, e também promove o armazenamento de substratos no tecido adiposo, no fígado e no músculo esquelético (Campos et al., 2005).

Já o glucagon tem por principal papel fisiológico estimular a produção metabólica do fígado, aumentando a concentração de glicose e corpos cetônicos no sangue (Sano et al., 1999). O glucagon estimula a glicogenólise, cetogênese e a gliconeogênese pelo fígado, a lipólise no tecido adiposo, a glicogenólise no músculo, mobilizando as reservas de glicogênio e diminui a glicólise, processos fundamentais para suprir as necessidades cerebrais (Engelking, 2010; Kolb, 1984). Assim sendo, em condições normais, a insulina é secretada na hiperglicemia e o glucagon na hipoglicemia, ou seja, no período pós-prandial há o aumento da secreção de insulina, que remove a glicose do sangue e estimula sua captação periférica nos músculos, fígado e adipócitos, e há diminuição do níveis séricos do glucagon; no período pré-prandial os níveis séricos de glicose se mantém através da produção hepática com o aumento da secreção de glucagon e inibição da secreção de insulina (Jennings et al., 2017).

\section{Alterações patológicas do pâncreas}

Várias doenças relacionadas ao metabolismo da glicose afetam o pâncreas, entre elas: neoplasias, cálculos, inflamações, atrofia, hiperplasia e distúrbios secretórios. O principal relato patológico em cães é a pancreatite, doença exócrina (Berman et al., 2020; Watson et al., 2010). Já na porção endócrina, a principal patologia é a Diabetes Mellitus, insulinoma e gastrinoma (Marcato, 2010). A inflamação da porção exócrina do pâncreas é chamada de Pancreatite e caracteriza-se pelos sinais clássicos da inflamação; podendo afetar outros órgãos e acarretando a maioria dos sintomas deste distúrbio. A pancreatite é causada por uma elaboração indevida de enzimas digestivas que destroem o tecido pancreático. Sua patogênese envolve a liberação de tripsina com causas multifatoriais, levando danos nos tecidos, causando aumento da permeabilidade capilar, ocasionando edema e possivelmente isquemia e necrose. Pode ocorrer em conjunto com outras patologias, podendo estar associada às infecções adenovirais sistêmicas, traumatismos, parasitos, ou lesões nos ductos pancreáticos ocasionando obstrução, sendo este último o principal caminho de agressão. A obstrução dos ductos pode ocorrer tanto em decorrência de inflamação e/ou presença de cálculos pancreáticos, toxinas, drogas, como os corticosteroides, quanto pela migração de parasitos (Moreira et al., 2017).

A pancreatite pode ocorrer de forma aguda ou crônica. A forma aguda é uma condição caracterizada principalmente por decorrência de vários graus de inflamação no pâncreas, os sintomas mais comuns são febre e depressão mental, também pode haver desidratação, diarreia, icterícia, arritmia e/ou sinais de hemorragias incluindo petéquias e equimoses. Já a pancreatite crônica é caracterizada por lesões anatômicas de caráter irreversível, geralmente de natureza progressiva, acompanhada de atrofia e fibrose do parênquima, com presença de infiltrados linfoplasmocíticos. As alterações macroscópicas aparentam uma massa nodular distorcida e encolhida, com aderências fibrosas ao tecido adjacente (Marcato, 2010). Geralmente, nenhuma destruição do tecido pancreático é de tamanho suficiente para causar insuficiência pancreática exócrina, e a fibrose pancreática geralmente é encontrada como uma lesão incidental na necropsia de cães com funcionamento aparentemente normal do sistema digestivo. O prognóstico da pancreatite é reservado a mau. A doença geralmente tem um longo curso clínico sendo também imprevisível. Pacientes com uma patologia subjacente como cetoacidose, DM, insuficiência renal aguda, sepse, doença hepática ou colestática tem um prognostico ruim (Moreira et al., 2017).

Outra patologia pancreática é a Atrofia Acinar Pancreática (AAP), ela é uma síndrome caracterizada pela redução do tecido acinar do pâncreas exócrino, reconhecido em várias raças de cães (Wiberg, 2004). Geralmente é identificado em cães com menos de 1 ano de idade, muito incidente na raça pastor alemão, e é caracterizada por sintomas clínicos de insuficiência pancreática exócrina crônica, e, geralmente aparecem após a perda de mais de $90 \%$ do parênquima funcional. Esta patologia é hereditária (autossômica) em cães de raças Pastor Alemão e ChowChow, e, acredita-se que sua patogênese seja autoimune, provavelmente via linfócitos T (Cunningham, 2011; Engelking, 2010; Kolb, 1984). O sinal clínico inicial é a esteatorreia devido à falta de absorção de nutrientes, aumento de volume do bolo fecal e perda de peso progressiva sem perda de apetite. Podendo ser encontrado também atrofia da musculatura esquelética e do tecido adiposo subcutâneo (Moreira et al., 2017). Atrofia pancreática acinar 
é a causa mais comum de insuficiência pancreática exócrina, assim é extremamente importante atenção nesses casos clínicos, observando o fator de predisposição hereditária (Pöppl \& González, 2005).

Outra patologia do pâncreas é a Insuficiência Pancreática Exócrina (IPE). Ela é o resultado da diminuição acentuada na produção de enzimas pelas células acinares. Pode ocorrer em decorrência de tumores pancreáticos, pancreatite crônica terminal, obstrução dos ductos pancreáticos, hiperacidez duodenal, e também em decorrência da AAP (Cunningham, 2011; Engelking, 2010; Kolb, 1984). É uma patologia delicada, pois, como o pâncreas exócrino tem uma reserva funcional significativa, isso faz com que os sinais clínicos não apareçam até que haja uma grande porção da glândula destruída. Há incidência em Pastor Alemão devido à predisposição da raça à atrofia pancreática exócrina, que pode desencadear IPE, e como consequência a destruição das ilhotas pancreáticas, o que favorece à DM intercorrente (Cunningham, 2011; Engelking, 2010; Kolb, 1984). Os sinais clínicos mais comuns são perda de peso progressivo, esteatorreia, polifagia, coprofagia, borborigmos e flatulência, atrofia da musculatura esquelética e do tecido adiposo subcutâneo (Cunningham, 2011; Engelking, 2010; Kolb, 1984). O tratamento consiste na suplementação de enzimas e na modificação da dieta, pois o ideal é uma dieta altamente digestível tendo baixo teor de gordura e fibra. Para diagnóstico de IPE, outras causas de má absorção devem ser excluídas, como a doença da mucosa do intestino delgado e lifangiectasia através da biópsia da mucosa intestinal, parasitismo crônico por exame fecal e DM (Cunningham, 2011; Engelking, 2010; Kolb, 1984).

O pâncreas é acometido pelas neoplasias conforme a linhagem celular, destacando-se os acinares, ductais e neuroendócrinos. No cão, destacam-se as neoplasias pancreáticas benignas: adenoma benigno das células $\beta$-pancreáticas, com células difusas nas ilhotas; e, as malignas: insolinoma e nesidioblastose, ocorrendo nas ilhotas pancreáticas. Geralmente a maioria de neoplasias em cães é de origem epitelial, chamados de adenocarcinoma ductal ou acinar e apresentam um padrão de crescimento expansivo e encapsulado criando assim espaços císticos pelas células de tumor (Bennett et al., 2001; Eosewicz \& Wiedenmann, 1997).

$\mathrm{O}$ adenocarcinoma tem seu aspecto pequeno e faz as concentrações séricas de amilase e lipase ficarem normais, porém quando os tumores são invasivos tem-se o resultado de pancreatite. $\mathrm{O}$ adenocarcinoma pode aparecer no epitélio acinar ou ductular e apresenta características dos mesmos tipos de epitélio, porém é possível fazer a diferenciação (Cunningham, 2011; Engelking, 2010; Kolb, 1984). O insulinoma é um tumor raro em cães, e é caracterizado pela produção excessiva de insulina. As causas geralmente são o adenoma benigno das células $\beta$-pancreáticas, a nesidioblastose, a microadenomatose difusa e a neoplasia maligna das ilhotas de Langerhans. Suas manifestações se dão por sintomatologia neurovegetativas e neuroglicopênicas e o tratamento é cirúrgico (Apodaca-Torrez et al., 2003).

\section{Diabetes mellitus canina}

Segundo a Associação Brasileira de Endocrinologia Veterinária (ABEV, 2018), a DM é considerada a principal doença pancreática endócrina nos cães, também chamada de DMC (Diabetes Mellitus Canina), e é representada como um grupo de doenças metabólicas autoimunes de múltiplas origens (Almeida, 2012; Marco et al., 1999). Na DM ocorre uma deficiência relativa ou absoluta de insulina que leva a uma insuficiência das células em obter e utilizar a glicose, que afeta a capacidade de obter e utilizar também aminoácidos, ácidos graxos e eletrólitos. A falta da insulina provoca alterações das vias glicolíticas, lipólise, cetogênese e do catabolismo proteico, alterando todo o metabolismo orgânico do animal. Vários processos patológicos podem convergir para estas desordens metabólicas levando ao conjunto de sinais que irão caracterizar esta doença (Almeida, 2012; Marco et al., 1999).

Sendo assim, a etiologia da DM é multifatorial, pois esses processos poderão variar individualmente, havendo alguns fatores considerados predisponentes, como a obesidade, hereditariedade, autoimunidade, infecções, inflamações, hipersecreção ou exposição prolongada aos hormônios diabetogênicos (como GH, adrenalina, glucagon, glicocorticoides etc), administrações exógenas de glicocorticoides ou progestágenos (Almeida, 2012; Marco et al., 1999). A presença de anticorpos (Ac) anti-células $\beta$ ou anti-insulina e/ou infiltrados inflamatórios no pâncreas endócrino não são constantes ou transversais a todos os pacientes diabéticos. Esta doença carece ainda de mais estudos e investigação; porém algumas etiopatogenias possíveis são a DM Idiopática, DM Imunomediada, por Predisposição 
Genética, secundária a Pancreatite Crônica, resultante do Antagonismo Hormonal, Tumores Endócrinos, Iatrogênica, e ainda, a DM Juvenil (Almeida, 2012; Marco et al., 1999).

Na DM Idiopática, se inclui a maioria das DM diagnosticadas, muito pela falta de um meio de diagnóstico etiológico da doença na pratica atual, mas à medida que novos conhecimentos vão se adquirindo sobre a mesma, essa atribuição etiológica irá diminuir. A etiologia da DM imunomediada se atribui o fato de que aproximadamente $50 \%$ do cães diabéticos diagnosticados têm anticorpos contra as células $\beta$-pancreáticas (Almeida, 2012; Marco et al., 1999). Segundo Catchpole et al. (2005) estes dados foram confirmados através do Western Blot que detecta anticorpos contra a pró-insulina canina recombinante, provando assim a evidência da autoimunidade na DMC (Almeida, 2012; Marco et al., 1999).

A etiologia relacionada à DM por predisposição genética vem do fato de que o processo de criação das raças puras, nos últimos 200 anos, ocasionou uma limitada variação genética, causando consequências para a saúde dos cães, elevando o aparecimento de doenças específicas em determinadas raças, a partir de mutações e enriquecimento de risco em determinados alelos (Almeida, 2012; Marco et al., 1999). A diabetes em cães foi associada aos genes do complexo de histocompatibilidade da classe II (gene leucocitário canino - DLA) com haplótipos e genótipos semelhantes aos alelos associados à DM tipo 1 em humanos, estes genes foram identificados em cães com maior suscetibilidade à diabetes e uma região contendo uma variação de repetições e polimorfismos foi também identificada no gene da insulina canina, com alelos associados à suscetibilidade ou resistência de maneira específica em determinadas raças (Nelson \& Reusch, 2014). Sendo assim, a predisposição genética é provada em algumas raças, mas nem sempre com as mesmas alterações genéticas (Almeida, 2012; Marco et al., 1999).

A pancreatite está envolvida na etiologia da DMC, posto que um terço dos animais diagnosticados tem ela como causa subjacente. Alguns estudos apontam que cães com pancreatite crônica perdem de maneira progressiva células $\beta$, se enquadrando assim num estado pré-diabético. A pancreatite parece também estar associada à complicação frequente da DMC, uma vez que é um achado frequente em necropsias, porém ainda existe uma falta de consenso nas conclusões sobre estudos histopatológicos do tecido pancreático de cães diabéticos relativo à presença de infiltração linfocítica nas ilhotas de Langerhans, definida como insulinite (Almeida, 2012; Marco et al., 1999).

Quanto à etiologia relacionada ao Antagonismo Hormonal, pode-se verifica-la em relação com outras doenças endócrinas nas quais a resistência à insulina pode conduzir a hiperglicemia crônica, que por sua vez, pode causar uma disfunção permanente nas células $\beta$-pancreáticas; como ocorre no caso da intolerância a carboidratos em decorrência de obesidade, por exemplo (Pöppl \& González, 2005). No Brasil, uma expressiva parcela de pacientes diabéticos é composta por fêmeas inteiras, cujo diagnóstico inicial se dá durante o diestro, o que evidencia um papel importante quanto ao excesso de secreção hormonal do GH (hormônio do crescimento) no tecido mamário, induzido pela progesterona. Esse processo diabetogênico em cadelas nos remete à DM gestacional humana, no qual diversos fatores imunológicos, genéticos e nutricionais podem aumentar o risco de diabetes durante esse período (ABEV, 2018).

Ainda sobre as doenças endócrinas, temos três tipos de oncologias como precedentes cronológicos da DMC: o hiperadrenocorticismo, a acromegalia e o glucagonoma. Acredita-se que a DM ocasiona pela Síndrome de Crushing se instala devido à resistência à insulina, antagonismo hormonal (hipercortisolismo) e glucotoxicidade (Pöppl \& González, 2005). Já na forma iatrogênica, acredita-se que a glucotoxicidade se dá devido à terapias orais ou parenterais com glucocorticóides, causando hipercortisolismo, reversível com a descontinuação terapêutica. Outros fármacos referidos como diabetogênicos são os progestágenos por ação anti-hormonal, que são conhecidos como "hormônios anti-cio", os inibidores do estro em cadelas (ex: medroxiprogestorona). A glucotoxicicade também pode ser verificada em cães pré-diabéticos, com pancreatite crônica ou com algum tipo de antagonismo hormonal (Almeida, 2012; Marco et al., 1999).

A etiologia da DM juvenil, está associada à hipoplasia das células $\beta$-pancreáticas ou de uma combinação entre a deficiência das mesmas e a atrofia pancreática exócrina (Pöppl \& González, 2005). Essa alteração vem sendo descrita sem alterações inflamatórias no tecido do pâncreas e os cães se apresentam insulinopênicos desde o início da doença (Almeida, 2012; Marco et al., 1999). 


\section{Apresentação clínica, diagnóstico e tratamento}

Atualmente, não há nenhum critério internacionalmente definido para a classificação da diabetes em cães e gatos (Faria, 2007; Pöppl \& González, 2005). Entretanto, na literatura encontra-se maneiras diferentes de classificar a DM em animais segundo modelo humano, levando em conta a etiologia e a patogênese da doença: diabetes mellitus tipo 1 (ou insulino-dependentes) e tipo 2 (não insulinodependentes). Quando encontramos os termos DM tipo 1 ou insulino-dependente, trata-se da forma caracterizada pela destruição das células $\beta$-pancreáticas, com uma perda progressiva ou completa da secreção do hormônio insulina. Quando encontramos os termos DM tipo 2 ou não insulino-dependente trata-se da forma caracterizada pela resistência dos tecidos periféricos à insulina, ou por uma insuficiência das células $\beta$-pancreáticas na produção e secreção da insulina. Todavia, na medicina veterinária, é preferível os termos DM de causa primária ou DM de causa secundária, devido ao fato de que a insulina é a base do tratamento em animais diagnosticados, uma vez que a resistência periférica a insulina que de início é compensada pelo aumento da produção da mesma, levará a uma exaustão e posteriormente destruição das células $\beta$-pancreáticas, perdendo assim sua funcionalidade (Faria, 2007; Pöppl \& González, 2005). Assim, temos como DMC primárias aquelas causadas por destruição das células $\beta$-pancreáticas, e, como DMC secundária, aquelas ligadas à resistência à insulina (Faria, 2007; Pöppl \& González, 2005).

Sob o ponto de vista clínico a DM reúne um conjunto de desordens diferentes que levam à hiperglicemia que se manifesta com um início insidioso que pode levar semanas até serem percebidas e a tendência é o diagnóstico tardio (Almeida, 2012; Marco et al., 1999). Os diagnósticos de DMC geralmente estão na faixa etária entre 4 e 14 anos, com pico de incidência entre sete e nove anos, sendo as fêmeas acometidas duas vezes mais que os machos. Algumas raças são mais acometidas como poodle, dachhound, beagle e schnauzer, mas todas as raças podem ser afetadas (Faria, 2007; Pöppl \& González, 2005).

O quadro clínico se dá com sintomatologia compatível associada a hiperglicemia e a glicosúria. Os sinais clínicos mais frequentes são: poliúria (excesso de micção), polidipsia (excesso de sede), polifagia (excesso de fome), glicosúria (presença de glicose na urina) e perda de peso. Os mecanismos destes sinais se dão a partir da falha no aporte glicêmico, ocasionada pela DM, que afeta o metabolismo e a fisiologia do animal, o que inclui as células tubulares renais que se tornam incapazes de realizar a absorção total da glicose, causando a glicosúria, que por sua vez ocasiona uma diurese osmótica, causando a poliúria. A insulina controla o centro de saciedade no hipotálamo, e, com a falta dela, a inibição da saciedade não ocorre e resulta numa polifagia e polidipsia (compensatória) (Faria, 2007; Pöppl \& González, 2005).

No exame clínico é frequente detectar perda de massa muscular, hepatomegalia, infecções de trato urinário e/ou respiratório, infecções de pele também são achados comuns no exame do cão diabético, por vezes podendo encontrar lesões ulcerativas. Cães com quadros complicados podem estar deprimidos, anoréxicos e desidratados, sintomas estes que estão diretamente associados a acumulação de corpos cetônicos que podem levar a acidose metabólica (Almeida, 2012; Marco et al., 1999).

Quanto às complicações da DMC, uma das mais graves é a acidose metabólica, que é ocasionada pela cetogênese hepática, lipólise e a mobilização das reservas corporais de ácido graxos livres, que alteram consideravelmente o equilíbrio ácido-base do organismo do animal. E, ambas podem levar o paciente à óbito. A hipoglicemia pode levar ao choque insulínico, coma e óbito, já a cetoacidose pode levar ao choque hipovolêmico, edema cerebral e consequentemente óbito (Gazzoni, 2016). Na clínica, segundo Nelson (1998), as complicações mais comuns incluem cegueira resultante da formação da catarata, pancreatite crônica e infecções do trato urinário, do sistema respiratório e da pele (Marco et al., 1999; Pöppl \& González, 2005). O reconhecimento destas complicações auxilia no diagnóstico e realização do tratamento adequado. Os fatores como idade, tipo de diabetes, tempo de diagnóstico, controle metabólico, obesidade e hipertensão arterial devem ser avaliados para evitar risco de complicações (Moreira et al., 2017).

O diagnóstico requer a presença dos sinais clínicos, somados a hiperglicemia em jejum e glicosúria persistente. A avaliação laboratorial completa é importante para estabelecer o diagnóstico e investigar outras enfermidades que possam causar ou contribuir com a doença, uma vez que a detecção de doenças concomitantes pode vir a modificar a terapia. Comumente encontra-se hemograma sem alterações, e as 
vezes como leucocitose neutrofílica (Faria, 2007; Pöppl \& González, 2005). Segundo Nunes (2014) o painel bioquímico apresenta: hiperglicemia, hipercolesterolemia, hipergliceridemia, aumento de alanino-aminotransferase e fosfatase alcalina, e o exame de urina tipo 1 apresenta glicosúria, cetonúria variável, proteinúria e bacteriúria (Faria, 2007; Pöppl \& González, 2005). A DM quando controlada adequadamente não possui um alta gravidade. A prerrogativa principal é de que o diagnóstico precoce é imprescindível para uma melhor qualidade de vida do paciente (Moreira et al., 2017).

Segundo Reusch (2010), o princípio do tratamento é a normalização dos valores glicêmicos, através do uso de insulinoterapia, agentes hipoglicemiantes (eventualmente), dietas específicas, exercícios físicos, remoção de qualquer fármaco diabetogênico, controle de doenças concomitantes (inflamatórias, infecciosas, endócrinas, neoplásicas etc) (Faria, 2007; Marco et al., 1999; Pöppl \& González, 2005). Também se faz necessário o monitoramento do paciente pelas constantes avaliações dos sinais clínicos, curva glicêmica seriadas, fuctosamina, hemoglobina glicolisada e quantificação da glicosúria (Meyrer, 2014). Para verificação da cetoacidose faz-se necessário também avaliar o pH pelos exames de gasometria arterial, a concentração de ácido acético na urina e a dosagem de $\beta \mathrm{HB}$ (ácido $\beta$ hidroxibutírico) sanguíneo, este último mais preferível do que os testes urinários (Gazzoni, 2016).

Outra questão a ser considerada no tratamento da DMC é quanto ao efeito Somogyi, ocasionado pela administração da insulina exógena, no qual ocorre uma resposta contra-regulatória do organismo (glicogenólise hepática e secreção de hormônios hiperglicemiantes) à hipoglicemia induzida por alta dosagem de insulina que, por sua vez, leva à hiperglicemia secundária repentina, como um efeito rebote, por um período de aproximadamente 12 horas, pois o paciente não consegue produzir insulina endógena para corrigir o quadro. A principal preocupação quanto ao efeito Somogyi é o fato de que a secreção de hormônios diabetogênicos durante este efeito pode induzir o metabolismo do animal à resistência à insulina em até 72 horas. Pacientes que apresentam o efeito Somogyi geralmente têm quadros e hipoglicemia $(<65 \mathrm{md} / \mathrm{dL})$ seguidos de hiperglicemia $(>300 \mathrm{mg} / \mathrm{dL})(\underline{\mathrm{ABEV}, 2018})$.

Outro ponto importante para ser ressaltado é relacionado a dieta. Há que se programar a dieta visando minimizar o aumento de glicemia pós-prandial, evitando assim flutuações glicêmicas (Faria, 2007; Pöppl \& González, 2005). No cão, isto é melhor atingido quando se utiliza uma dieta com elevado teor de fibras e baixo teor de gorduras, porém, há que se levar sempre em consideração as doenças concomitantes, como insuficiência renal crônica, pancreatite, litíase urinária, obesidade etc, para a escolha da dieta adequada, uma vez que a doença concomitante pode vir a ter uma prioridade sob esta escolha (Meyrer, 2014).

\section{Fisiologia e histopatologia do pâncreas na diabetes mellitus canina}

A DMC se apresenta por uma disfunção do pâncreas endócrino que se manifesta por uma hiperglicemia crônica que pode levar a destruição das células $\beta$-pancreáticas através da exaustão e perda de função (Faria, 2007; Pöppl \& González, 2005). Sendo assim, as principais alterações histológicas em cães com DMC incluem a redução do número e volume das ilhotas de Langerhans, diminuição das células $\beta$-pancreáticas e vacuolização e degeneração das mesmas (Pöppl \& González, 2005). Em cães adultos, isso pode ocorrer devido a fatores ambientais, como doenças e drogas antagonistas a insulina, e a pancreatite. Em cães jovens, pode ocorrer de forma mais agressiva, culminando na deficiência absoluta das células $\beta$ e hipoplasia ou aplasia das ilhotas. Estudos descrevem a presença de infiltração linfocitária (raras) e anticorpos nas ilhotas, em casos de insulinite imunomediada. Também foi descrito, depósitos amilódes nas ilhotas de Langerhans e que predispõe ao desenvolvimento de glucotoxicidade quando expostas à hiperglicemia prologada (Feldman et al., 2014; Nelson \& Reusch, 2014; Reusch, 2010).

Muito importante comentar, do ponto de vista fisiológico sistêmico, que o antagonismo hormonal e a glicotoxicidade, são comuns em diagnósticos de diabetes em cadelas inteiras no período do diestro. Esse antagonismo está associado à progesterona e o hormônio do crescimento $(\mathrm{GH})$, pois ambos hormônios competem com os receptores de insulina na parede celular, induzindo a resistência à insulina, levando a cadela a um estado diabético que após a gestação poderá ser revertida ou, na pior das hipóteses, progredir para a diabetes mellitus canina (Almeida, 2012; Marco et al., 1999). Nesses casos, o mecanismo diabetogênico se dá, pois, este hormônio $(\mathrm{GH})$ age como antagonista à insulina, e, o excesso de secreção do mesmo exige uma maior secreção de insulina pelas células $\beta$-pancreáticas, o que pode acarretar numa exaustão da capacidade de secreção destas células, especialmente no caso de existir 
outros mecanismos predisponentes (ABEV, 2018). Outro hormônio importante é o cortisol, que pode alterar o metabolismo da glicose, ao inibir a secreção de insulina pelas células $\beta$-pancreáticas, e, ao agir em tecidos musculares e hepatócitos, estando diretamente associado à resistência à insulina de maneira severa, que ocasiona hiperinsulinemia (Pöppl \& González, 2005).

Já na etiopatogenia da DM juvenil, o ponto mais importante é que podemos verificar alterações associadas principalmente à histologia do pâncreas, com a presença de hipoplasia das células $\beta$ pancreáticas ou de uma combinação entre a deficiência das mesmas e a Atrofia Acinar Pancreática. Na histologia da atrofia acinar, verifica-se apoptose das células acinares, perda de grânulos de zimogênios e alterações vacuolares no citoplasma das células, perda das ilhotas de Langerhans e atrofia lobular (Almeida, 2012; Marco et al., 1999).

\section{Considerações Finais}

O pâncreas é uma glândula mista que pode ser acometido por diversas doenças que causam alterações significantes que prejudicam todo o metabolismo do animal. Algumas alterações no pâncreas exócrino são advindas da diabetes mellitus canina como consequência, porém o contrário também é possível, pois patologias pancreáticas, como a Insuficiência Pancreática Exócrina (IPE) e/ou inflamações crônicas, como é o caso da pancreatite, podem favorecer o surgimento da DMC. E, ainda, patologias endócrinas como a acromegalia e o hiperadrenocorticismo, também favorecem a DMC. Todavia, a total compreensão dos efeitos dos distúrbios metabólicos ocasionados por patologias pancreáticas e a DMC carecem de mais estudos, tanto para classificar melhor a doença, como para evidenciar mais especificamente sua etiopatogenia, uma vez que há divergências entre autores.

O consenso atual é de que a DMC é uma patologia multifatorial de alta incidência na clínica de pequenos animais e caracteriza-se pela hiperglicemia relacionada a uma falha do pâncreas endócrino na produção e secreção de insulina, mais especificamente com uma incapacidade das ilhotas pancreáticas em secretar a insulina, e também pela ação deficiente da insulina nos tecidos ocasionados pela resistência periférica, tanto de forma imunomediada quanto por ocasião de glucotoxicidade. Os mecanismos autoimunes em conjunto com fatores genéticos e ambientais, drogas antagonistas da insulina e doenças adjacentes, têm um papel importante para o desenvolvimento e a progressão da DMC, tendo como resultado final a perda de função das células $\beta$-pancreáticas. Essa perda de função é irreversível e a terapia com insulina exógena se dará para toda a vida do animal. Todavia, devemos ressaltar que o próprio tratamento da DMC é um fator de extrema importância na ocorrência de complicações das doenças, pois o manejo inadequado pode trazer consequência danosas para o paciente, como é o caso do efeito Somogyi.

A histologia refere-se destruição parcial ou total das ilhotas de Langerhans, vacuolização e/ou degeneração hidrópica, presença de infiltração leucocitária, embora divergente entre autores, e anticorpos quando da etiologia imunomediada; depósitos amilóides também foram descritos predispondo à glucotoxicidade. Em cães jovens, a forma mais agressiva da doença ocasiona a deficiência total das células $\beta$-pancreáticas e pode-se verificar hipoplasia ou aplasias das ilhotas de Langerhans.

\section{Referências bibliográficas}

ABEV - Associação Brasileira de Endocrinologia Veterinária. (2018)Diabetes Mellitus Canina e Felina. Manual clínico. 72p. Disponível em: < https://vetsmartparsefiles.s3.amazonaws.com/b7f467e6f8893ed68555d698415ef7dc_streaming_attachment.pdf > Acesso em 10 abril 2021 às 14:20

Almeida, P. A. M. (2012). Estudo retrospectivo sobre potenciais fatores de risco para a diabetes mellitus canina. Universidade Lusófona de Humanidades e Tecnologia.

Apodaca-Torrez, F. R., Triviño, T., Lobo, E. J., Goldenberg, A., \& Figueira, A. (2003). Insulinomas do pâncreas: diagnóstico e tratamento. Arquivos de Gastroenterologia, 40, 73-79. https://doi.org/10.1590/s0004-28032003000200003.

Balarin, M. R. S., Lopes, R. S., Kohayagawa, A., Laposy, C. B., \& Fonteque, J. H. (2005). Avaliação da glicemia e da atividade sérica de aspartato aminotransferase, creatinoquinase, gamaglutamiltransferase e lactato desidrogenase em eqüinos puro sangue inglês (PSI) submetidos a 
exercícios de diferentes intensidades. Semina: Ciências Agrárias, 26(2), 211-218.

Banks, W. J., \& Rangel, F. S. (1986). Histologia veterinária aplicada (Issue 636.0891018 B355H.). Manole.

Bennett, P. F., Hahn, K. A., Toal, R. L., \& Legendre, A. M. (2001). Ultrasonographic and cytopathological diagnosis of exocrine pancreatic carcinoma in the dog and cat. Journal of the American Animal Hospital Association, 37(5), 466-473. https://doi.org/10.5326/15473317-37-5-466.

Berman, C. F., Lindquist, E., \& Lobetti, R. G. (2020). Comparison of clinical findings in 293 dogs with suspect acute pancreatitis: Different clinical presentation with left lobe, right lobe or diffuse involvement of the pancreas. Journal of the South African Veterinary Association, 91(1), 1-10. https://doi.org/10.4102/JSAVA.V91I0.2022.

Bloom, C. A., \& Rand, J. (2014). Feline diabetes mellitus: clinical use of long-acting glargine and detemir. Journal of Feline Mdicine and Surgery, 16(3), 205-215.

Campos, R., González, F., Coldebella, A., \& Lacerda, L. (2005). Determinação de corpos cetônicos na urina como ferramenta para o diagnóstico rápido de cetose subclínica bovina e relação com a composição do leite. Archives of Veterinary Science, 10(2). https://doi.org/10.5380/avs.v10i2.4413.

Catchpole, B., Ristic, J. M., Fleeman, L. M., \& Davison, L. J. (2005). Canine diabetes mellitus: can old dogs teach us new tricks? Diabetologia, 48(10), 1948-1956. https://doi.org/10.1007/s00125-005-1921-1.

Cunningham, J. (2011). Tratado de fisiologia veterinária. Guanabara Koogan.

Dukes, H. H., Reece, W. O., Figueiredo, C., Vanzellotti, I. R., \& Zanon, R. F. (2006). Fisiologia dos animais domésticos (Vol. 1). Guanabara Koogan.

Dyce, K. M., Wensing, C. J. G., \& Sack, W. O. (2004). Tratado de anatomia veterinária. Elsevier Brasil.

Engelking, L. R. (2010). Fisiologia endócrina e metabólica em medicina veterinária. Roca.

Eosewicz, S., \& Wiedenmann, B. (1997). Pancreatic carcinoma. The Lancet, 349(9050), 485-489.

Eurell, J. A., \& Frappier, B. L. (2012). Histologia Veterinária de Dellmann (Vol. 1). Guanabara Koogan.

Faria, P. F. (2007). Diabetes mellitus em cães. Acta Veterinária Brasílica, 1(1), 8-22. https://doi.org/10.21708/avb.2007.1.1.258.

Feldman, E. C., Nelson, R. W., Reusch, C., \& Scott-Moncrieff, J. C. (2014). Canine and feline endocrinology. Elsevier Health Sciences.

Gazzoni, C. P. (2016). Cetoacidose diabética em cães e gatos: revisão de literatura. Universidade Federal do Rio Grande do Sul.

Gilor, C., Niessen, S. J. M., Furrow, E., \& DiBartola, S. P. (2016). What's in a name? Classification of diabetes mellitus in veterinary medicine and why it matters. Journal of Veterinary Internal Medicine, 30(4), 927-940. https://doi.org/10.1111/jvim.14357.

Herrtage, M. E. (2001). Doenças do sistema endócrino. In J. K. Dunn (Ed.), Tratado de medicina de pequenos animais (pp. 523-568). Roca.

Hugen, G. F. G. P. (2017). Estudo retrospectivo de neoplasmas do sistema digestório em caninos. Programa de Pós-Graduação em Veterinária.

IBGE - Instituto Brasileiro de Geografia e Estatística. Pesquisa nacional de saúde - 2019: Percepção do estado de saúde, estilos de vida, doenças crônicas e saúde bucal. Rio de Janeiro: IBGE, 2020. 113p. Disponível em: <https://biblioteca.ibge.gov.br/visualizacao/livros/liv101764.pdf > Acesso em 10 abril 2021 às 12:54

IDF, International Diabetes Federation. Fatos e números sobre a diabetes - in: nona edição 2019 do IDF Diabetes Atlas 2019. Disponível em: < https://www.idf.org/aboutdiabetes/what-is-diabetes/factsfigures.html > Acesso em 10 abril 2021 as 13:34

Jennings, R., Premanandan, C., Ciancolo, R., Wilkie, D., Wong, A., \& Kendzioski, J. (2017). Veterinary histology. Ohio State University Libraries.

Kolb, E. (1984). Fisiologia veterinária. Koogan.

Köning, H. E., \& Liebich, H. G. (2011). Anatomia dos animais domésticos texto e atlas colorido. Editora Artmed.

Marcato, J. A. (2010). Pancreatite em cães.

Marco, V. (2015). Doenças do sistema endócrino e do metabolismo. In M. Jericó, J. P. Neto, \& M. Kogika (Eds.), Tratado de medicina interna de cães e gatos. Guanabara - Koogan.

Marco, Viviani, Amaral, R. C., Jericó, M. M., Silva, R. D., \& Simões, D. M. (1999). Diagnóstico de 
Diabetes mellitus na espécie canina e avaliação a longo prazo da terapia insulínica através das concentrações séricas de hemoglobina glicosilada. Revista de Educação Continuada Em Medicina Veterinária e Zootecnia Do CRMV-SP, 2(2), 23-28. https://doi.org/10.36440/recmvz.v2i2.3382.

Meyrer, B. (2014). Diabetes mellitus: monitorando o tratamento. In Seminário (p. 11 p.). Universidade Federal do Rio Grande do Sul.

Moreira, T. A., Gundim, L. F., \& Medeiros, A. A. (2017). Patologias pancreáticas em cães: revisão de literatura. Arquivos de Ciências Veterinárias e Zoologia Da UNIPAR, 20(2), 109-115.

Nelson, R. W., \& Reusch, C. E. (2014). Animal models of disease: classification and etiology of diabetes in dogs and cats. Journal of Endocrinology, 222(3), T1-T9. https://doi.org/10.1530/JOE-14-0202.

Nunes, N. J. S. (2014). Diabetes mellitus felina: ênfase em métodos de diagnóstico.

Pöppl, Á. G., \& González, F. H. D. (2005). Aspectos epidemiológicos e clínico-laboratoriais da diabetes mellitus em cães. Acta Scientiae Veterinariae, 33(1), 33-40. https://doi.org/10.22456/1679-9216.14436.

Reusch, C. (2010). Feline diabetes. In S. J. Ettinger \& E. C. Feldman (Eds.), Textbook of veterinary internal medicine (pp. 1796-1816). Saunders.

Rocha, M. B. (2018). Fatores de risco para diabetes mellitus felina: revisão de literatura. Universidade Federal do Rio Grande do Sul.

Rucinsky, R., Cook, A., Haley, S., Nelson, R., Zoran, D. L., \& Poundstone, M. (2010). AAHA diabetes management guidelines for dogs and cats. Journal of the American Animal Hospital Association, 46(3), 215-224. https://doi.org/10.5326/0460215.

Samuelson, P. (2011). Tratado de histologia veterinária. Elsevier Health Sciences.

Sano, H., Arai, H., Takahashi, A., Takahashi, H., \& Terashima, Y. (1999). Insulin and glucagon responses to intravenous injections of glucose, arginine and propionate in lactating cows and growing calves. Canadian Journal of Animal Science, 79(3), 309-314. https://doi.org/10.4141/A98-115

Sisson, S., Grossman, J. D., \& Getty, R. (1986). Anatomia dos animais domésticos. Interamericana.

Sparkes, A. H., Cannon, M., Church, D., Fleeman, L., Harvey, A., Hoenig, M., Peterson, M. E., Reusch, C. E., Taylor, S., \& Rosenberg, D. (2015). ISFM consensus guidelines on the practical management of diabetes mellitus in cats. Journal of Feline Mdicine and Surgery, 17(3), 235-250.

Tavernari, F. C., \& Mendes, A. M. P. (2009). Desenvolvimento, crescimento e características do sistema digestório de aves. Revista Eletrônica Nutritime, 6(6), 1103-1115.

Watson, P. J., Archer, J., Roulois, A. J., Scase, T. J., \& Herrtage, M. E. (2010). Observational study of 14 cases of chronic pancreatitis in dogs. Veterinary Record, 167(25), 968-976. https://doi.org/10.1136/vr.c4912.

Wiberg, M. E. (2004). Pancreatic acinar atrophy in German shepherd dogs and rough-coated Collies. Etiopathogenesis, diagnosis and treatment. A review. Veterinary Quarterly, 26(2), 61-75. https://doi.org/10.1080/01652176.2004.9695169.

Histórico do artigo:

Recebido: 14 de junho de 2021

Aprovado: 13 de julho de 2021
Licenciamento: Este artigo é publicado na modalidade Acesso Aberto sob a licença Creative Commons Atribuição 4.0 (CC-BY 4.0), a qual permite uso irrestrito, distribuição, reprodução em qualquer meio, desde que o autor e a fonte sejam devidamente creditados. 